\title{
Performance Analysis of Thermal Energy Storage Prototype in Thailand
}

\author{
R. Boonsu, S. Sukchai, S. Hemavibool, and S. Somkun
}

\begin{abstract}
The experiment was performed on thermal energy storage prototype in Thailand. Concrete was used as the solid media sensible heat material because it is locally available, is easy to handle and is low cost. Water/Steam was used for HTF. The concrete storage prototype was composed of concrete with embedded pipes. The embedded pipes were used transporting and distributing the heat transfer medium while sustaining the pressure. The concrete stores the thermal energy as sensible heat. The heat exchanger was composed of 16 tubes of high temperature steel with an inner diameter of $12 \mathrm{~mm}$ and wall thickness of $7 \mathrm{~mm}$. The tubes were arranged in a $4 \times 4$ square arrangement with a separation of $82 \mathrm{~mm}$. A storage prototype was $0.5 \times 0.5 \times 4 \mathrm{~m}$. The charging water/steam temperature was maintained at $180^{\circ} \mathrm{C}$ with the flow rates of $0.009,0.0012$ and $0.014 \mathrm{~kg} / \mathrm{s}$ whereas the inlet temperature of the discharge water/steam was maintained at $110^{\circ} \mathrm{C}$. Thermal performance of Thermal Energy Storage such as Charging and discharging times, radial thermal distribution, energy storage capacity and energy efficiency have been evaluated. For the charging/discharging experiment, it was found that the increase or decrease in storage temperature depends on the HTF temperature, flow rates, and initial temperature. The results showed that increasing the HTF flow rate increases the overall heat transfer coefficient, thereby enabling faster exchange of heat and reduces charging time. The results from this research can be a guideline for thermal storage system design for solar thermal power plant in Thailand.
\end{abstract}

Index Terms-Thermal energy storage, heat transfer fluid (HTF), concrete, prototype, performance.

\section{INTRODUCTION}

Solar energy is one of the most promising alternative energy options to conventional fossil fuels. However, the intermittent availability of solar energy leads to an energy gap between demand and supply. On sunny days the solar energy collected is usually more than the energy required to meet immediate demand, and on overcast days the supply is insufficient. Therefore, the design and development of efficient and economical thermal energy storage (TES) systems is of vital importance [1]. Basically, there are three methods of storing thermal energy: sensible heat storage,

Manuscript received February 9, 2015; revised May 23, 2015. This work was supported by a research scholarship of the Energy Policy and Planning Office (EPPO), Ministry of Energy and The National Science and Technology Development Agency (NSTDA), Ministry of Science and Technology, Thailand.

R. Boonsu, S. Sukchai, and S. Somkun are with the School of Renewable Energy Technology, Naresaun University, Phitsanulok, 65000 Thailand (e-mail: rungrudee_b@hotmail.com, Sukruedeen@nu.ac.th, Sakdaso@nu.ac.th).

S. Hemavibool is with the Department of Civil Engineering, Naresaun University, Phitsanulok, 65000 Thailand (e-mail: saranagonh@nu.ac.th). latent heat storage and thermo-chemical storage. A sensible heat storage unit stores thermal energy by changing the temperature of a storage medium, either a solid or a liquid [2].

The ability of a given material to store sensible heat depends on the value of its energy density, which is the heat capacity per unit volume, and its conductivity. The economics of this mode of heat storage demands sensible heat storage material which is inexpensive [1]. Solid materials such as cast steel, stone, rock, sand, concrete and ceramic have usually been selected as sensible heat storage media depending on the required temperature range and specific application. The TES system using concrete as the sensible heat storage media is usually implemented by embedding the pipes heat exchanger in concrete to transfer thermal energy to or from the heat transfer fluid, air, and synthetic oil. The advantages of using a concrete system include the low cost of the thermal storage media, the high heat transfer rates into and out of concrete, the ease of handling of the material, the availability of the material, and uncomplicated processing. Concrete systems provide all of these advantages and are therefore an attractive option for use in parabolic trough power plant. As well, they are relatively maintenance free. Khare et al. [3] studied candidate materials for high temperature sensible heat storage (SHS) systems. The main difficulty in using solid media for SHS is the large size requirement of the storage bed. However, this can be minimized by using high heat capacity storage materials and allowing high temperature swing. Tamme et al. [4] suggested castable ceramic and concrete as sensible heat storage mediums for high temperature heat storage applications. Laing et al. [5] investigated ceramic and high temperature concrete for maximum storage temperatures up to $663^{\circ} \mathrm{K}$ with storage capacity of $350 \mathrm{~kW}$. He concluded that concrete was the more preferable storage material although ceramic has $20 \%$ higher storage capacity and $35 \%$ greater conductivity. Nandi et al. [6] reported concrete and castable ceramic as low cost (25-30 \$ kWh) and durable SHS systems. It has been observed that heating the concrete at elevated temperatures causes certain reactions and transformations to occur due to the presence of voids which influence their thermo-physical properties. The compressive strength decreases by about $20 \%$ on heating the concrete to $673 \mathrm{~K}$ [1]. However, such problems can be minimized by the addition of filler materials such as steel needles and reinforcement to improve the mechanical and thermal strength of the material. John et al. [7] found that after exposure to 10 thermal cycles with temperature increases from ambient temperature to 723 $\mathrm{K}$, the concrete bed maintained more than $50 \%$ of its mechanical properties. It can be seen from the previous work that many researchers emphasized the use of high temperature concrete as a SHS material. However, there is a lack of 
research on solid SHS systems based on using water/steam as the heat transfer fluid. The present work seeks to remedy this perceived lack by investigating the thermal storage performance of solid state SHS systems, using local concrete material, in Thailand, under the various climatic conditions to be found in Thailand.

\section{TheOry of Thermal EnERgy StORAGe PERFormance}

The overall storage process of the thermal energy storage process is shown in Fig. 1.

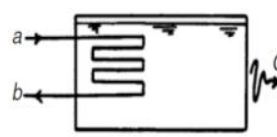

(a)

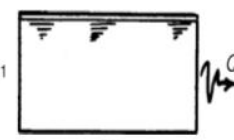

(b)

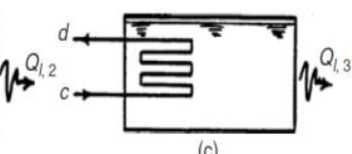

Fig. 1. The three stage in a simple heat storage; charging period (a), Storage period (b), and discharging period (c) [8].

\section{A. Storage Equation}

The storage system is the sensible heat in solid storage medium. An energy balance for the overall storage process can be written as [8]

Energy Input $-($ Energy Recovered + Energy Loss $)=$ Energy Accumulation

or

$$
\dot{m}\left(h_{a}-h_{b}\right)-\left[\dot{m}\left(h_{d}-h_{c}\right)+Q_{l}=\Delta E\right.
$$

where $h_{a}, h_{b}, h_{c}$ and $h_{d}$ are the total enthalpies of the flows at states $a, b, c$, and $d$, respectively, and $Q_{l}$ denotes the heat loss during the process and $\Delta E$ is the accumulation of energy in the TES. $\left(h_{a}-h_{b}\right)$ represents the net heat delivered to the TES and $\left(h_{d}-h_{c}\right)$ the net heat recovered from the TES.

\section{B. Charging Period}

Charging time is the time taken for the stored bed's volume average temperature to reach a specified rise in temperature $\Delta T$. An energy balance for the charging period can be written as follows [8]:

$$
\text { Energy Input -Energy Loss = Energy Accumulation }
$$

or

$$
\begin{gathered}
\dot{m}\left(h_{a}-h_{b}\right)-Q_{l, 1}=\Delta E 1 \\
\Delta E 1=E_{f, 1}-E_{i, 1}
\end{gathered}
$$

$E_{i, 1}$ and $E_{f, 1}$ denote the initial and the final energy of the TES for the charging period and $Q_{l, 1}$ denotes the heat loss during the period. $h_{a}$ and $h_{b}$ denote the enthalpy of state $a$ and $b$.

\section{Discharging Period}

Discharging time is the time taken for the storage bed to attain a volume average temperature of $T_{\text {inlet }}$. An energy balance for the discharging period can be written as [8]

$-($ Energy Input + Energy Loss $)=$ Energy Accumulation $(4)$

$$
\begin{gathered}
-\left[\dot{m}\left(h_{d}-h_{c}\right)+Q_{l, 3}\right]=\Delta E_{3} \\
\Delta E_{3}=E_{f, 3}-E_{i, 3}
\end{gathered}
$$

$E_{i, 3}\left(=E_{f, 2}\right)$ and $E_{f, 3}$ denote the initial and final energies of the storage for the discharging period. The quantity in square brackets represents the energy output during discharging.

\section{Energy efficiency}

Energy efficiency is the ratio of energy recovered from the thermal energy storage during discharging to the total energy input during charging. The energy efficiency $(\eta)$ can be defined as [8]:

$$
\begin{gathered}
\eta=\frac{\text { Energy recovered from TES during discharging }}{\text { Energy input to TES during charging }} \\
\eta=\frac{h_{d}-h_{c}}{h_{a}-h_{b}}
\end{gathered}
$$

\section{EXPERIMENTAL PROCESS}

\section{A. Experimental Instruments}

The concrete storage prototype was composed of pipes embedded in a concrete storage block. The embedded pipes are used for transporting and distributing the heat transfer medium while sustaining the pressure. The concrete storage stores the thermal energy as sensible heat. A special interface material was installed to reduce the friction between the concrete and the pipes due to the mismatch of thermal expansion.

The heat exchanger was composed of 16 pipes of high-temperature steel with the inner diameter of $12 \mathrm{~mm}$ and wall thickness of $7 \mathrm{~mm}$. They were distributed in a square arrangement of 4 by 4 pipes with a separation of $82 \mathrm{~mm}$. The storage prototype had the dimensions of $0.5 \times 0.5 \times 4 \mathrm{~m}$.

In order to record data for energy balances, the piping system was equipped with numerous of sensors. The mass flow as well as the water/steam temperature and pressure were measured. The prototype was equipped with 56 thermocouples distributed within the storage material, on the embedded pipes and the header pipe. After the installation of additional reinforcement and measuring equipment, a formwork was installed and the storage space was filled with the thermal storage concrete. The storage prototype was then covered by insulation on all sides and top and bottom (see Fig. 2-Fig. 3).

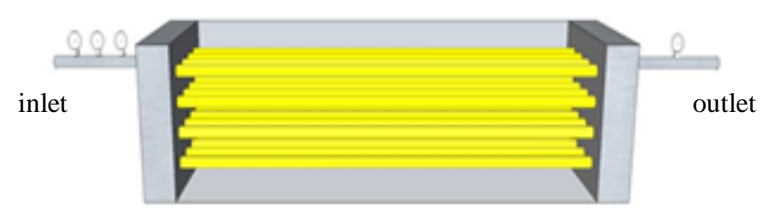

Fig. 2. Schematic of thermal storage. 


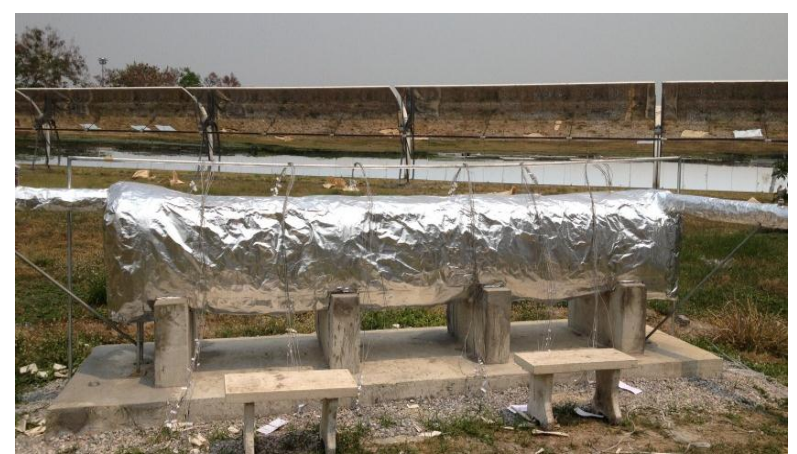

Fig. 3. Thermal storage prototype.

TABLE I: THERMOPHYSICAL PROPERTIES OF STORAGE PROTOTYPE FROM THE LABORATORY

\begin{tabular}{lcl}
\hline \hline \multicolumn{1}{c}{ Parameter } & Values & Unit \\
\hline Density of the concrete & 1820 & $\mathrm{~kg} / \mathrm{m}^{3}$ \\
Specific heat capacity of the concrete & 1538 & $\mathrm{~J} / \mathrm{kg} \cdot \mathrm{K}$ \\
Thermal conductivity of the concrete & 1.0352 & $\mathrm{~W} / \mathrm{m} \cdot \mathrm{K}$ \\
Coefficient thermal expansion of ther concrete & 8.21 & $10^{-6} / \mathrm{K}$ \\
Coefficient thermal expansion of the tubes & 12.3 & $10^{-6} / \mathrm{K}$ \\
Density of the HTF & 5.14 & $\mathrm{~kg} / \mathrm{m}^{3}$ \\
Specific heat capacity of the HTF & 2556 & $\mathrm{~J} / \mathrm{kg} \cdot \mathrm{K}$ \\
Thermal conductivity of the HTF & $36.61 \times 10^{-3}$ & $\mathrm{~W} / \mathrm{m} \cdot \mathrm{K}$ \\
\hline \hline
\end{tabular}

\section{B. Experimental Procedure}

The experimental investigation was carried out at the Energy Park of the School of Renewable Energy Technology (SERT) at Naresuan University, Phitsanulok, Thailand.

As the startup procedure, prior to the experimental processes proper, most of the water contained in the concrete was expelled by heating the concrete storage prototype from ambient temperature to $180^{\circ} \mathrm{C}$. During the process the water evaporates and there is a buildup of vapor pressure within the concrete. During this process there was a buildup of vapor pressure within the concrete which needed to be carefully monitored to avoid damage to the concrete.

The subsequent operating conditions of the concrete storage prototype were:

- Heat transfer fluid (water/steam)

- Maximum internal pressure (10 bar)

- Maximum temperature: up to $180{ }^{\circ} \mathrm{C}$

- Test temperature range between 110-180 C

- Mass flow rate: $0.009,0.012$ and $0.014 \mathrm{~kg} / \mathrm{s}$

\section{RESULT AND DISCUSSION}

\section{A. Charging Time}

Having completed the startup procedure, the first charging experiment was commenced. As shown in Fig. 4, the HTF inlet temperature and the storage prototype temperature were plotted for comparison of the HTF temperature and the average temperature of the storage prototype during this first charging experiment.

During the tests, HTF inlet mass flow rates were 0.009, 0.012 and $0.014 \mathrm{~kg} / \mathrm{s}$. The HTF inlet temperature to the storage prototype was manually increased very quickly to about $180{ }^{\circ} \mathrm{C}$ and then maintained at an almost constant level at about $180{ }^{\circ} \mathrm{C}$ for most of the charging process. Also, as shown in Fig. 4, the storage prototype temperature slightly increased. This is shown at the different flow rates in Fig. 4 Initially the volume average temperature of the storage bed rose rapidly and then rose slowly over the subsequent time up to 180 minutes. This is due to the initial potential for heat conduction in the concrete. The heat conduction potential decreases with time as the storage bed gains heat of the HTF.

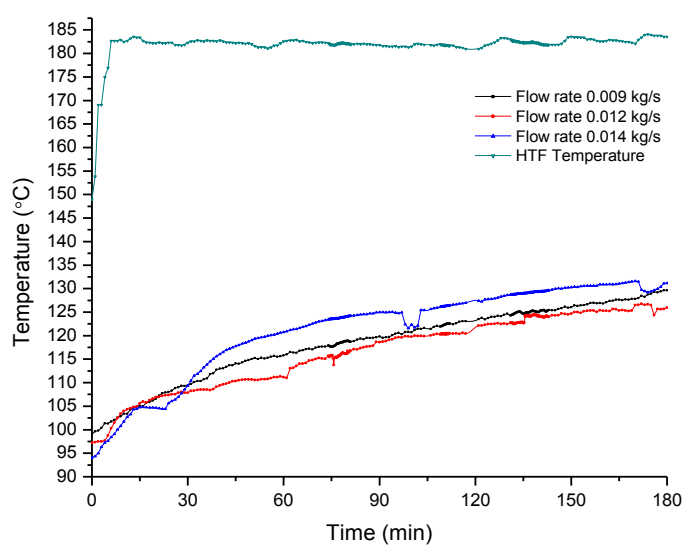

Fig. 4. Temperature of HTF inlet and storage prototype in charging experiment at $0.009,0.012$ and $0.014 \mathrm{~kg} / \mathrm{s}$.

\section{B. Energy Input}

The thermal energy rates at the storage bed of the storage prototype were shown in Fig. 5.

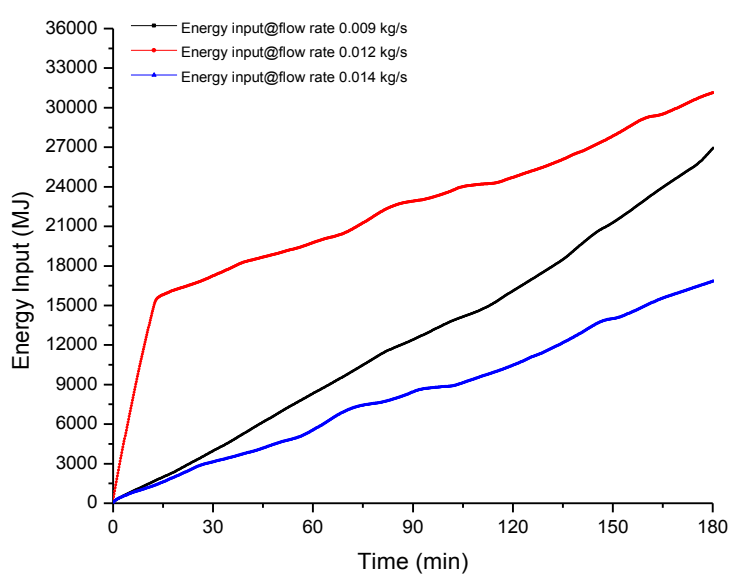

Fig. 5. Energy input during charging process at $0.009,0.012$ and $0.014 \mathrm{~kg} / \mathrm{s}$.

The amount of thermal energy input in the storage materials at their respective charging times was calculated using Equation (2). The flow rate of $0.012 \mathrm{~kg} / \mathrm{s}$ resulted in the fastest heat transfer from the pipe to the concrete, followed by the flow rate of $0.009 \mathrm{~kg} / \mathrm{s}$ with $0.014 \mathrm{~kg} / \mathrm{s}$ the lowest heat transfer value. The energy input at the various flow rates were $0.012 \mathrm{~kg} / \mathrm{s}, 31,119 \mathrm{MJ}, 0.009 \mathrm{~kg} / \mathrm{s}, 26,891 \mathrm{MJ}$ and $0.014 \mathrm{~kg} / \mathrm{s}$, $16,840 \mathrm{MJ}$.

\section{Radiant Thermal Distribution on Charging Time}

The radiant thermal distribution for thermal energy storage over charging time is shown in Fig. 6(a)-Fig. 6(c). Increasing the HTF flow rate increases the overall heat transfer coefficient enabling faster exchange of heat which reduces the 
charging time. At higher HTF flow rates the time required to achieve a certain temperature decreased. At the HTF flow rate of $0.014 \mathrm{~kg} / \mathrm{s}$ the temperature increase over time was greatest, followed by the flow rate of $0.012 \mathrm{~kg} / \mathrm{s}$ with the flow rate of $0.009 \mathrm{~kg} / \mathrm{s}$ being the slowest.

Fig. 6(a)-Fig. 6(c) show the comparisons of thermal distribution of temperature by thermal radiation for the three flow rates through the $1 \mathrm{~cm}, 2 \mathrm{~cm}$ and $3 \mathrm{~cm}$ from $\mathrm{HTF}$ pipe respectively.

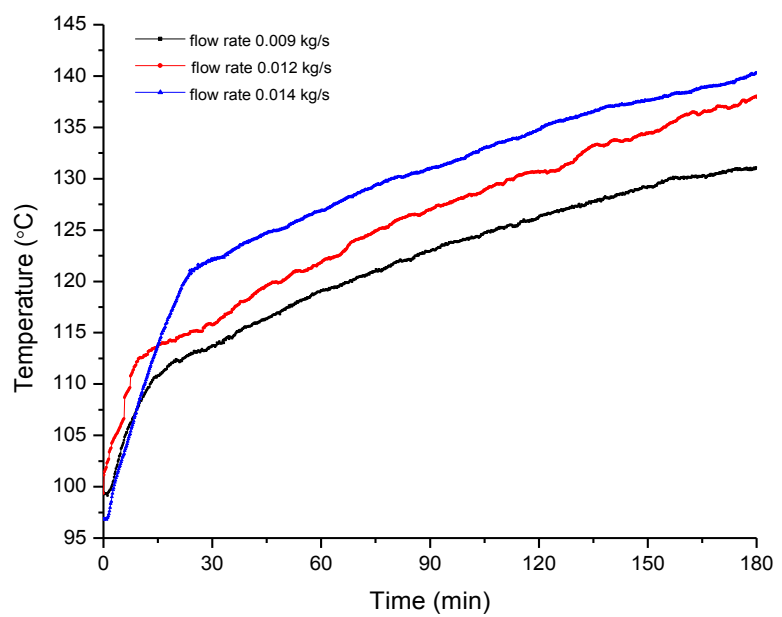

(a)

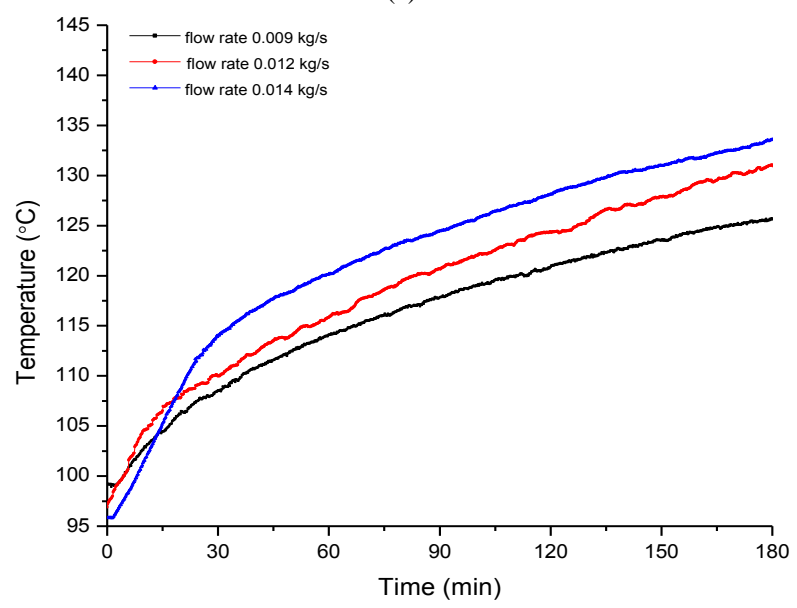

(b)

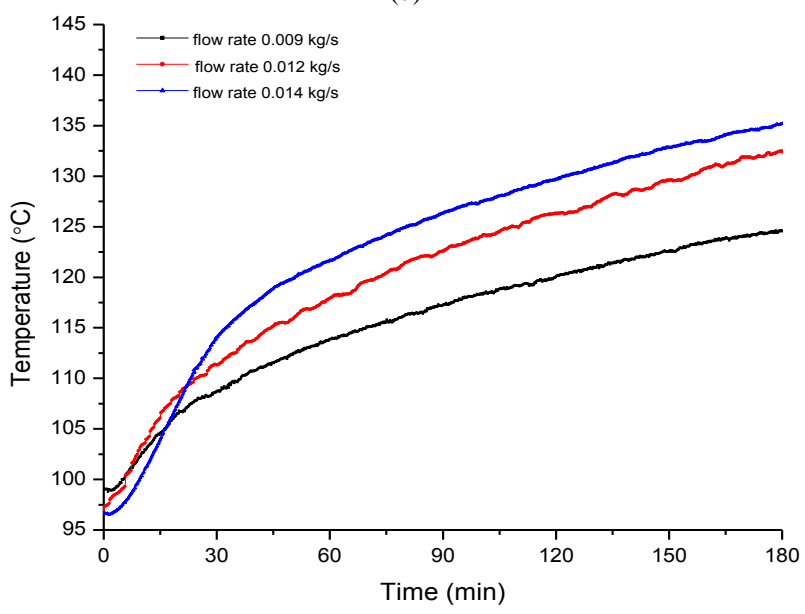

(c)

Fig. 6. Radial thermal distribution and flow rate on charging time of storage bed.

\section{Discharging Time}

During the discharge process, various thermocouples were fixed inside the storage material in order to measure the temperature distribution. The average temperature of the storage material inside the thermal storage prototype decreased over time (Fig. 7).

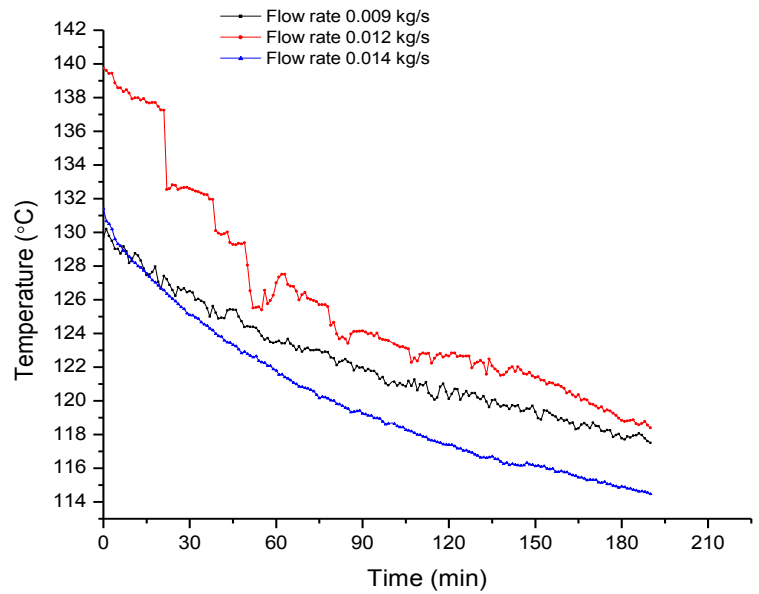

Fig. 7. Temperature of concrete storage prototype in discharging period at $0.009,0.012$ and $0.014 \mathrm{~kg} / \mathrm{s}$.

\section{E. Energy Recovered}

The thermal energy recovery rates of the storage bed are shown in Fig. 8. The amount of thermal energy recovered was calculated using Equation (4). The calculations showed that at the flow rate of $0.014 \mathrm{~kg} / \mathrm{s}$ the heat transfer from the concrete into the pipe was faster than at the flow rates of 0.012 and $0.009 \mathrm{~kg} / \mathrm{s}$. The energy recovered at each flow rate was, at $0.014 \mathrm{~kg} / \mathrm{s}, 18,796 \mathrm{MJ}$, at $0.012 \mathrm{~kg} / \mathrm{s}, 14,363 \mathrm{MJ}$ and at 0.009 $\mathrm{kg} / \mathrm{s}, 12,173 \mathrm{MJ}$.

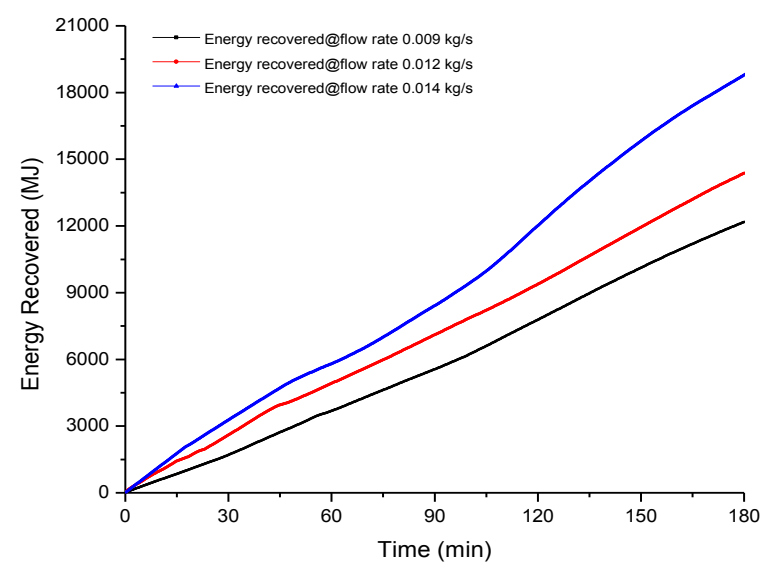

Fig. 8. Energy recovered during discharging period at $0.009,0.012$ and $0.014 \mathrm{~kg} / \mathrm{s}$.

\section{F. Radial Thermal Distribution on Discharging Time}

Heat discharge of the charged storage bed was initiated by passing HTF at a lower temperature $\left(\mathrm{T}_{\text {inlet }}\right)$; The HTF receives the heat from the charged storage bed which decreases the storage bed temperature and also causes a rise in the HTF temperature along the bed. The radiant thermal distribution for thermal energy storage on discharging time is shown in Fig. 9(a)-Fig. 9(c), which show comparison of the thermal distribution of temperature of thermal radiation for the $1 \mathrm{~cm}, 2$ $\mathrm{cm}$ and $3 \mathrm{~cm}$ HTF pipes. It can be seen that the decrease in discharging time of the storage bed with HTF at the flow rate of $0.014 \mathrm{~kg} / \mathrm{s}$ was faster than that of $0.012 \mathrm{~kg} / \mathrm{s}$ with $0.009 \mathrm{~kg} / \mathrm{s}$ being the lowest value. 


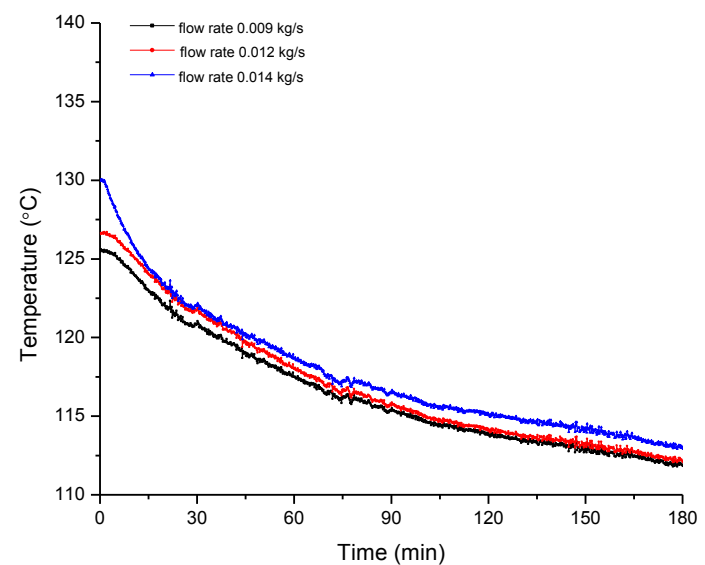

(a)

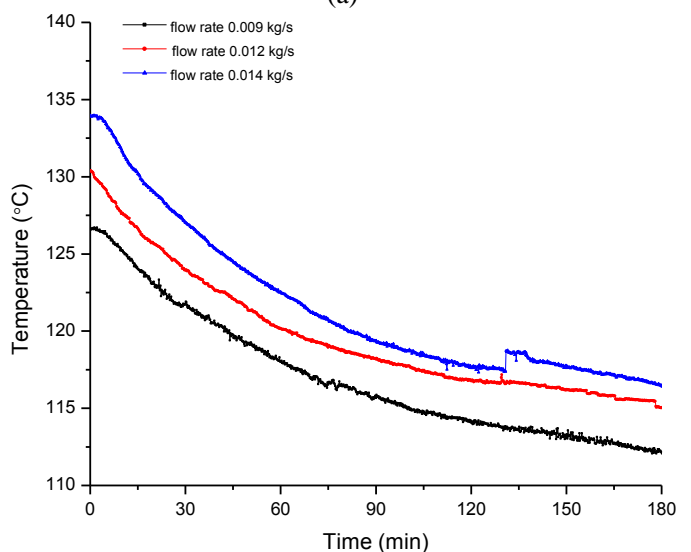

(b)

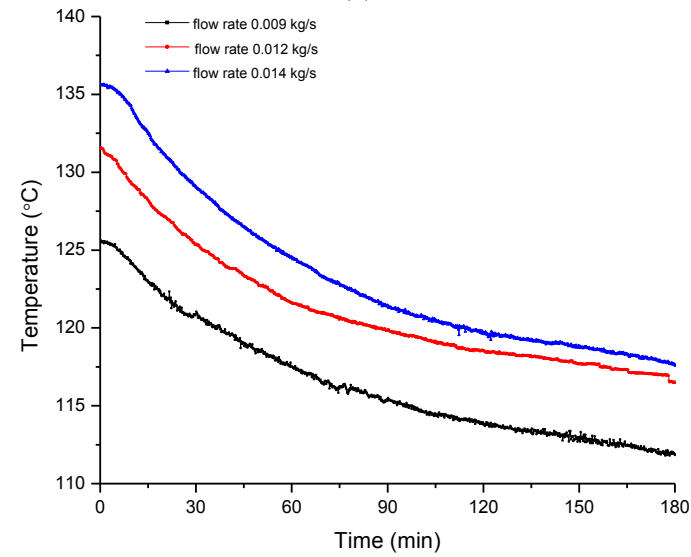

(c)

Fig. 9. Radial thermal distribution and flow rate on discharging time of storage bed.

\section{G. Energy Efficiency}

The energy was degraded in the process of storage since it was extracted at a temperature lower than that at which it was previously stored. The energy efficiency of the storage bed was evaluated using Equation 6. Fig. 10 shows the energy efficiency of the thermal energy storage prototype. The flow rate of $0.012 \mathrm{~kg} / \mathrm{s}$ dramatically increased in the first 45 minute after which time it increased gradually while the efficiency at the flow rate of $0.014 \mathrm{~kg} / \mathrm{s}$ increased sharply and at the flow rate of $0.009 \mathrm{~kg} / \mathrm{s}$ increased slightly, while seeming to stabilize at a later time.

For 135 minutes of operation, the energy efficiency was $52 \%$ at the flow rate of $0.012 \mathrm{~kg} / \mathrm{s}$ while the flow rate of 0.014 gave $47 \%$ energy efficiency. The flow rate of $0.009 \mathrm{~kg} / \mathrm{s}$ gave $37 \%$ for 150 minutes operational time.

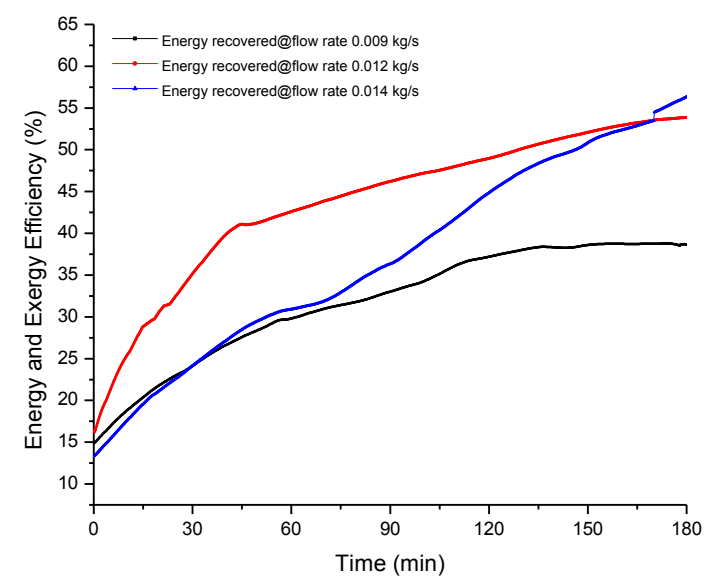

Fig. 10. Energy efficiency of thermal energy storage prototype at 0.009 0.012 and $0.014 \mathrm{~kg} / \mathrm{s}$.

\section{CONCLUSIONS}

In this paper, the performance analysis of a thermal energy storage prototype is presented. For the charging/discharging experiment, it was found that the increase or decrease in storage temperature depends on the HTF temperature, flow rates, and initial temperature.

The results showed that increasing the HTF flow rate increases the overall heat transfer coefficient, thereby enabling faster exchange of heat and reduces charging time.

In the charging period, the heat transfer from the flow pipes to the concrete storage medium were $31,119 \mathrm{MJ}$ for flow rate of $0.012 \mathrm{~kg} / \mathrm{s}$, the fastest heat transfer rate, $26,891 \mathrm{MJ}$ for the flow rate of 0.009 and $16,840 \mathrm{MJ}$ for the $0.014 \mathrm{~kg} / \mathrm{s}$ flow rate.

The energy recovered over the discharging period was $18,796 \mathrm{MJ}$ for flow rate of $0.012 \mathrm{~kg} / \mathrm{s}$, the fastest heat transfer rate, $14,363 \mathrm{MJ}$ for the flow rate of 0.009 and $12,173 \mathrm{MJ}$ for the $0.014 \mathrm{~kg} / \mathrm{s}$ flow rate.

The energy efficiency at the flow rate of $0.012 \mathrm{~kg} / \mathrm{s}$ dramatically increased in the first 45 minutes after which it increased gradually. For the flow rate of $0.014 \mathrm{~kg} / \mathrm{s}$, the energy efficiency increased sharply and at the flow rate of $0.009 \mathrm{~kg} / \mathrm{s}$ it increased slightly and then seemed to stabilized.

Over 135 minutes of operation, the energy efficiency was $52 \%$ at the flow rate of $0.012 \mathrm{~kg} / \mathrm{s}$ while the flow rate of 0.014 gave $47 \%$ energy efficiency. Meanwhile the flow rate of $0.009 \mathrm{~kg} / \mathrm{s}$ gave $37 \%$ for 150 minutes operational time.

The results from this research can be a guideline for thermal storage system design for Commercial Solar Thermal Power Plant in Thailand.

\section{REFERENCES}

[1] A. Gil, M. Medrano, I. Martorell, and F. Cabeza, "State of the art on high temperature thermal energy storage for power generation. Part 1-Concepts, materials and modellization," Renewable and Sustainable Energy Reviews, vol. 14, pp. 31-55, 2010.

[2] A. Abhat, "Low temperature latent heat thermal energy storage: Heat storage materials," Solar Energy, vol. 30, pp. 313-332, 1983.

[3] S. Khare, C. Knight, and S. McGarry, "Selection of materials for high temperature sensible energy storage," Solar Energy Materials and Solar Cells, vol. 115, pp. 114-122, 2013.

[4] R. Tamme, D. Laing, and W. Steinmann, "Advanced thermal energy storage technology for parabolic trough," Journal of Solar Energy Engineering, vol. 126, pp. 794-800, 2004.

[5] D. Laing, W. Steinmann, R. Tamme, and C. Richter, "Solid media thermal storage for parabolic trough power plants," Solar Energy, vol. 86 , pp. $1283-1289,2006$. 
[6] B. R. Nandi, S. Bandyopadhyay, and R. Banerjee, "Analysis of high temperature thermal energy storage for solar power plant," in Proc. the 3rd IEEE International Conference on Sustainable Energy Technology, 2012, pp. 438-444.

[7] E. E. John, W. M. Hale, and R. P. Selvam, "Development of a high-performance concrete to store thermal energy for concentrating solar power plants," in Proc. the 5th ASME International Conference on Energy Sustainability, 2011, pp. 523-529.

[8] I. Dincer and M. A. Rosen, "Thermal energy storage," Systems and Applications, vol. 55, 2011.

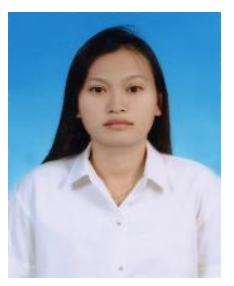

Rungrudee Boonsu is a Ph.D. candidate studying renewable energy in the School of Renewable Energy Technology, Naresuan University, Phitsanulok, Thailand. Her research interests include thermal energy storage, solar energy technology, concentrating solar energy power plants and biomass energy.

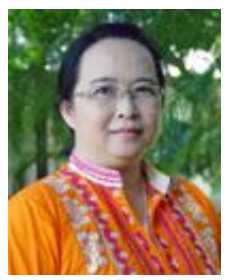

Sukruedee Sukchai is the director of the School of Renewable Energy Technology, Naresuan University, Phitsanulok, Thailand. Her research interests include solar energy technology, concentrating solar energy power plant, thermal energy storage and solar drying.

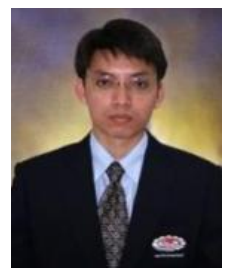

Saranagon Hemavibool is a lecturer in the Department of Civil Engineering, Faculty of Engineering, Naresuan University, Phitsanulok, Thailand. His research interests are in the microstructure of cementitious materials and their engineering properties, fiber reinforced concrete, early-age cracking of concrete and the use of waste materials in concrete.

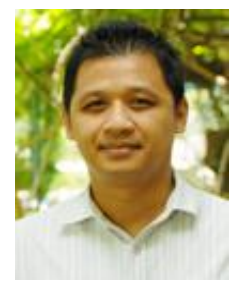

Sakda Somkun is a lecturer in the School of Renewable Energy Technology, Naresuan University, Phitsanulok, Thailand. His reseach interests are in power electronic interfacing for renewable energy and development of measurement standards for magnetic flux density. 